\title{
Locked Neglected Posterior Shoulder Dislocation-Outcome
}

\author{
Muhammad Ali*, MA Wajid and Marium Zafar \\ Shalamar Medical and Dental College, Lahore, Pakistan
}

Submission: July 23, 2018; Published: August 10, 2018

*Corresponding author: Muhammad Ali, Shalamar Medical and Dental College, Lahore, Pakistan, Tel: 00923215470768 ;

Email: muhammadali19782002@yahoo.com

\section{Introduction}

Posterior dislocation of the shoulder joint is a rare entity accounting for less than $2 \%$ of all shoulder 1,2 dislocations. The injury is misdiagnosed in $50 \%$ to $79 \%$ of patients, most commonly due to lack of critical physical examination and inadequate radiographic examination or insufficient radiograph reading skills of the attending physician. The main causes of dislocations are trauma, seizures, or electric shock[1-7]. The diagnosis is suspected in patients with a palpable prominence of the coracoid, increased palpable prominence of the humeral head in the posterior aspect of the shoulder, and a complete loss of external rotation [8].

An anteroposterior view and axillary view (if tolerated by patient) is helpful to reach the diagnosis[9]. Computed tomography can identify the involvement of the articular surface of the humeral head and fractures of the tuberosity, surgical neck, and glenoid. Magnetic resonance imaging is useful rare cases to reveal cuff tears and posterior labrum lesions. Treatment modalities vary and depend on the size of the humeral head defect, the duration of dislocation, and the degree of instability. Numerous surgical techniques have been described for the management of this injury, including disimpaction with elevation and bone grafting of the defect, transposition of the subscapularis tendon or the lesser tuberosity into the defect, rotational osteotomy of the proximal humerus, and hemi- or total shoulder arthroplasty for large defects and neglected dislocations[3-6].

\section{Materials and Methods}

Between January 2014 and December 2016, we performed retrospective analysis of four patients ( 5 shoulders) with locked neglected posterior shoulder dislocation treated by a single orthopedic surgeon in a private setting. Causes of posterior shoulder dislocation in our study were trauma in two cases while other two had electric shock. One case with electric shock was bilateral.The patients' average age was 43 years (range 25-58 years), while the mean follow up was 11 months (range 6-18 months).All the patients in our series were males and the dominant shoulder was affected in 3 cases. All the patients were evaluated by plain radiographs pre and postoperatively. Each patient underwent open reduction and capsular shift with subsequent immobilization and physical therapy.

\section{Surgical Technique}

We performed an open reduction of the shoulder joint using deltopectoral approach with the patient in beach chair position under general anesthesia. The lower edge of the subscapularis tendon was identified and tagged with proline suture. To expose the humeral head and glenoid the subscapularis tendon and capsule were elevated. Reduction was done carefully using an elevator to prevent further damage to the head and glenoid. Stability of the shoulder joint was evaluated preoperatively clinically and through fluoroscopy to see the entire range of motion. Temporary stabilization of shoulder joint with Kirschner wires was unnecessary. One patient required filling of the bone defect by lesser tuberosity. The wound was closed in layers using a suction drain. The shoulder was immobilized using a brace for a period of 6 weeks. We restricted Internal rotation of the shoulders during this time period. Physical therapy was initiated, including passive, active-assisted, and progressively active range of motion and rotator cuff strengthening exercises. Full activity was allowed at 12 weeks postoperatively.

\section{Results}

We use UCLA scoring system. Mean follow-up was 11 months (range, 6-18 months). Mean range of shoulder motion was $162^{\circ}$ of flexion range, $150^{\circ}-175^{\circ}$ ) $69^{\circ}$ of external rotation (range, $55^{\circ}-80^{\circ}$ ), $48^{\circ}$ of internal rotation (range, $40^{\circ}-55^{\circ}$ ), and $140^{\circ}$ of abduction (range, $130^{\circ}-155^{\circ}$ ). At last follow-up, all patients were asymptomatic with painless and stable shoulder joints without sign of instability. Mean Constant score used to evaluate patient satisfaction was $84 \%$ (range, 77\%-90\%).All patients were very satisfied with their level of function with no restrictions. In all cases, radiographs showed the humeral head to be satisfactory reduced in relation to the glenoid (Figures 1\&2) and (Tables $1 \& 2)$. 


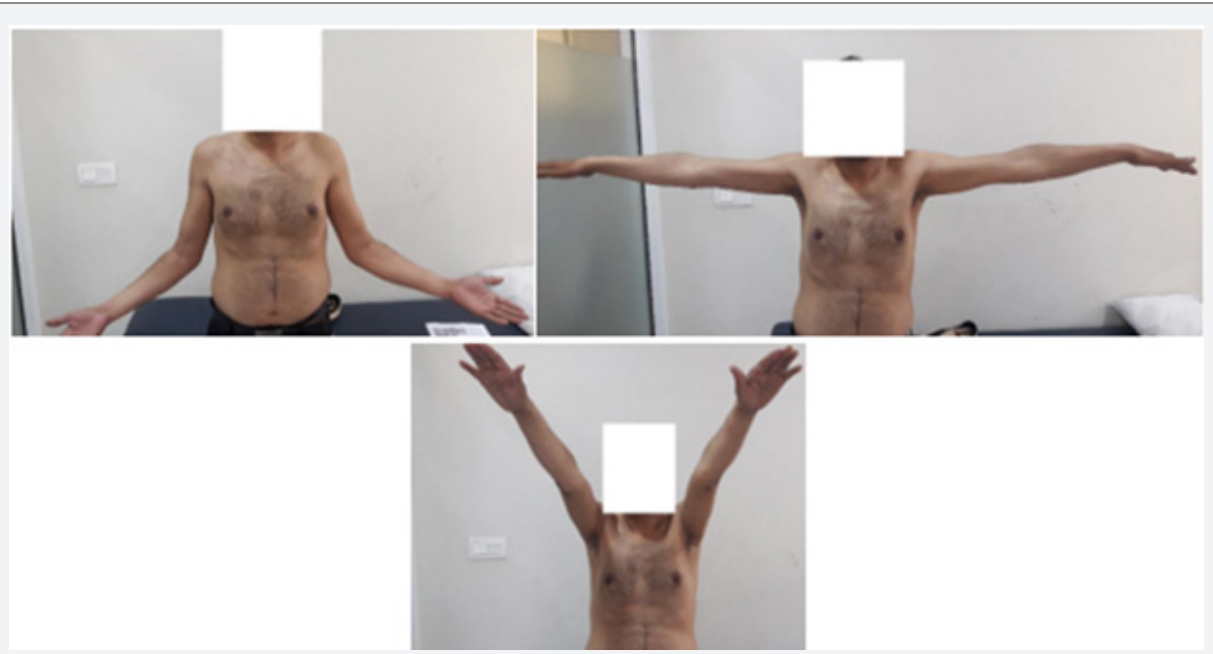

Figure 1: Clinical photographs of patient at 18-month follow-up showing abduction $\left(135^{\circ}\right)(A)$, flexion $\left(175^{\circ}\right)(B)$, and external rotation $\left(80^{\circ}\right)$ (C).

\section{UCLA Shoulder rating scale}

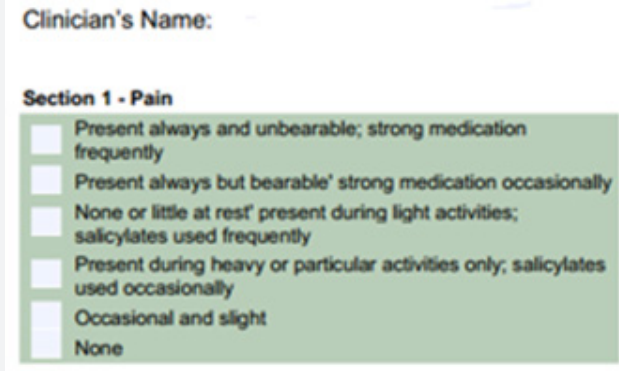

Section 3 - Active forward flexion

\begin{tabular}{l} 
Section 3 - Active forward flexion \\
$150^{\circ}$ \\
$120^{\circ}-150^{\circ}$ \\
$90^{\circ}-120^{\circ}$ \\
$45^{\circ}-90^{\circ}$ \\
$30^{\circ}-45^{\circ}$ \\
$<30^{\circ}$ \\
\hline
\end{tabular}

Sections - Satisfaction of patient

Satisled and better

Not satisfied and worse

\section{Patient's Name}

\section{Section 2 - Function}

Unable to use limb

Only light activities possible

Able to do light housework or most activities of daily living

Most housework, shopping, and driving possible; able to do

hair and to dress and undress, including fastening bra

Slight restriction only, able to work above shoulder level

Normal activities

Section 4-Strength of forward flexion (manual muscle testing)

Grade 5 (normal)

Grade 4 (good)

Grade 3 (fair)

Grade 2 (poor)

Grade 1 (muscle concentration)

Grade 0 (nothing)

Total UCLA Shoulder score is:

Figure 2

Table 1: Details of Patients with Neglected Locked Posterior Dislocation of the Shoulder.

\begin{tabular}{|c|c|c|c|c|}
\hline Patient No./Sex/Age, $\mathbf{y}$ & Shoulder & Mechanism of Injury & $\begin{array}{c}\text { Time from Injury to } \\
\text { Surgery, wk. }\end{array}$ & Follow up months \\
\hline $1 / \mathrm{M} / 37$ & $\mathrm{R}$ & Trauma & 4 & 12 \\
\hline $2 / \mathrm{M} / 52$ & $\mathrm{R}$ & Trauma & 8 & 6 \\
\hline $3 / \mathrm{M} / 58$ & $\mathrm{R}$ & Electric shock & 16 & 18 \\
\hline $4 / \mathrm{M} / 25$ & $\mathrm{R}$ & Electric shock & 12 & 18 \\
\hline
\end{tabular}


Table 2

\begin{tabular}{|c|c|c|c|c|c|}
\hline Patient No./Sex/Age, $\mathbf{y}$ & UCLA Score & Flexion & Abduction & External rotation & Internal rotation \\
\hline 1/M/37 & 29 & 165 & 130 & 65 & 55 \\
\hline $2 / \mathrm{M} / 52$ & 25 & 160 & 140 & 70 & 40 \\
\hline $3 / \mathrm{M} / 58$ & 28 & 150 & 155 & 55 & 50 \\
\hline $4 / \mathrm{M} / 25$ & 29 & 175 & 140 & 75 & 50 \\
\hline & 30 & 160 & 135 & 69 & 45 \\
\hline Mean & 28.2 & 162 & 140 & & 48 \\
\hline
\end{tabular}

\section{Discussion}

Posterior shoulder dislocation is a rare entity. Once it is diagnosed, the management depends on the amount of the defect of the humeral head and the time from injury. The size of the humeral head impaction fracture is key to the decision process[10]. Defects of the articular surface of the humeral head up $50 \%$ of the articular surface should be treated with shoulder arthroplasty[11,12]. The management of defects between $25 \%$ and $50 \%$ are more challenging. Our study has some short comings. There were small number of cases. We have short follow up and there was no comparative group[13-23].

\section{Conclusion}

Management of neglected, locked posterior shoulder dislocation is difficult and diagnosis is often delayed, making treatment even more challenging. Traditional techniques have had limited success with closed reduction in the chronic situation. Open reduction is the mainstay of treatment in neglected locked posterior shoulder dislocation.

\section{References}

1. Cheng Sl, Mackay MB, Richards RR (1997) Treatment of locked posterior fracture-dislocations of the shoulder by total shoulder arthroplasty. J Shoulder Elbow Surg 6(1):11-17.

2. Hawkins RJ, Neer CS II, Pianta RM, Mendoza FX (1987) Locked posterior dislocation of the shoulder. J Bone Joint Surg Am69(1):9-18.

3. McLaughlin HL (1952) Posterior dislocation of the shoulder. J Bone Joint Surg Am 24(3):584-590.

4. Hatzis N, Kaar TK, Wirth MA, Rockwood CA Jr (2001) The often overlooked posterior dislocation of the shoulder. Tex Med97(11):6267.

5. Jones TP, Beckenbaugh JP, Sperling JW, Amrami KK, Sundaram M (2003) Your diagnosis? Posterior shoulder dislocation. Orthopedics26(7): 682,745-746.

6. Porteous MJ, Miller AJ (1990) Humeral rotation osteotomy for chronic posterior dislocation of the shoulder. J Bone Joint Surg Br72(3):468469.

7. Kelly JP (1954) Fractures complicating electro-convulsive therapy and chronic epilepsy. J Bone Joint Surg Br36(1):70-79.

8. Brown RJ (1984) Bilateral dislocation of the shoulders. Injury 15(4):267-273.

9. Wallace WA, Hellier M (1983) Improving radiographs of the injured shoulder. Radiography49(586):229-233.
10. Cicak N (2004) Posterior dislocation of the shoulder. J Bone Joint Surg Br86(3):324-332.

11. Loebenberg MI, Cuomo F (2000) The treatment of chronic anterior and posterior dislocations of the glenohumeral joint and associated articular surface. Orthop Clin North Am 31(1): 23-34.

12. Page AE, Meinhard BP, Schulz E, Toledano B (1995) Bilateral posterior fracture-dislocation of the shoulders: Management by bilateral shoulder hemiarthroplasties. J Orthop Trauma 9(6): 526-529.

13. Aparicio G, Calvo E, Bonilla L, Espejo L, Box R (2000) Neglected traumatic posterior dislocations of the shoulder: Controversies on indications for treatment and new CT findings. J Orthop Sci5(1):37-42.

14. Hottya GA, Tirman PFJ, Bost FW, Montgomery WH, Wolf EM, et al. (1998) Tear of the posterior stabilizers after posterior dislocation: MR imaging and MR arthrographic findings with arthroscopic correlation. AJR Am J Roentgenol171(3):763-768.

15. Chen AL, Hunt SA, Zuckerman JD (2005) Humeral head impression fractures and head-splitting fractures. In: Zuckerman JD, Koval KJ, (Eds.); Shoulder Fractures: The Practical Guide to Management. New York, Thieme, pp. 120-143.

16. Dubousset J (1967) Posterior dislocations of the shoulder [in French] Rev ChirOrthopReparatriceAppar Mot 53(1):65-85.

17. Gerber C, Lambert SM (1996) Allograft reconstruction of segmental defects of the humeral head for the treatment of chronic locked posterior dislocation of the shoulder. J Bone Joint Surg Am78(3):376382.

18. Keppler P, Holz U, Thielemann FW, Meinig R (1994) Locked posterior dislocation of the shoulder: treatment using rotational osteotomy of the humerus. J Orthop Trauma8(4):286-292.

19. Finkelstein JA, Waddell JP, O'Driscoll SW, Vincent G (1995) Acute posterior fracture dislocations of the shoulder treated with the Neer modification of the McLaughlin procedure. J Orthop Trauma9(3):190-193.

20. Charalambous CP, Gullett TK, Ravenscroft MJ (2009) A modification of the McLaughlin procedure for persistent shoulder instability: Technical note. Arch Orthop Trauma Surg 129(6):753-755.

21. Checchia SL, Santos PD, Miyazaki AN (1998) Surgical treatment of acute and chronic posterior fracture dislocation of the shoulder. J Shoulder Elbow Surg 7(1):53-65.

22. Gerber C (1991)L'instabilitépostérieure de l'épaule. In: Cahiers d'Enseignement de la SOFCOT. Paris, France: Expansion ScientifiqueFrançaise, pp. 223-245.

23. Bock P, Kluger R, Hintermann B (2007) Anatomical reconstruction for reverse Hill-Sachs lesions after posterior locked shoulder dislocation fracture: A case series of six patients. Arch Orthop Trauma Surg127(7):543-548 
This work is licensed under Creative Commons Attribution 4.0 License

DOI: 10.19080/JPFMTS.2018.04.555655
Your next submission with Juniper Publishers will reach you the below assets

- Quality Editorial service

- Swift Peer Review

- Reprints availability

- E-prints Service

- Manuscript Podcast for convenient understanding

- Global attainment for your research

- Manuscript accessibility in different formats ( Pdf, E-pub, Full Text, Audio)

- Unceasing customer service

Track the below URL for one-step submission https://juniperpublishers.com/online-submission.php 